DOI 10.37882/2223-2982.2021.11.13

\title{
ОРГАНИЗАЦИОННО-ПЕДАГОГИЧЕСКИЕ УСЛОВИЯ ОРГАНИЗАЦИИ ПРОФЕССИОНАЛЬНОГО ОБУЧЕНИЯ СТАРШЕКЛАССНИКОВ НА УРОВНЕ СРЕДНЕГО ОБЩЕГО ОБРАЗОВАНИЯ
}

\section{ORGANIZATIONAL AND PEDAGOGICAL CONDITIONS FOR THE ORGANIZATION OF VOCATIONAL TRAINING OF HIGH SCHOOL STUDENTS AT THE LEVEL OF SECONDARY GENERAL EDUCATION}

S. Kovalenko N. Belokopytova A. Lutkova

Summary: The article describes the organizational and pedagogical conditions for the organization of vocational training of high school students within the framework of the development of the basic general education program of secondary general education, based on the experience of a general education organization. The relevance of the stated topic reflects the innovative activity of a general education organization in the context of the implementation of the basic educational program of secondary general education, integrated with the basic program of vocational training in the profession of a worker / position of an employee. The purpose of this study is to theoretically substantiate and provide work experience on the implementation of organizational and pedagogical conditions for the organization of vocational training of high school students at the level of secondary general education. In the study, the materials reflect the innovative activity of a general education organization in the context of the implementation of the basic educational program of secondary general education, integrated with the basic program of vocational training in the profession of a worker / position of an employee. The methods of theoretical analysis, concretization, generalization, synthesis, deduction, modeling are used. The authors describe the conditions for the implementation of the basic educational program of secondary general education, integrated with the basic program of vocational training in the profession of a worker / position of an employee, which will allow educational organizations to design and implement basic educational programs taking into account regional specifics and the specifics of the educational organization, the characteristics of the contingent of students in full compliance with federal state educational standards of general education. The article characterizes the description of organizational and pedagogical conditions for the organization of vocational training of high school students within the framework of the development of the basic general education program of secondary general education, based on the experience of a general education organization. The presented model of the regional basic educational program of secondary general education reveals the technology of designing basic educational programs in general education organizations, taking into account: a) the peculiarities of the region; $b$ ) the content of the concepts of modernization of subject areas (information technology, chemistry); c) the specifics of the

\section{Коваленко Светлана Николаевна}

директор, МКОУ «Средняя общеобразовательная школа №9 города Аши Челябинской области

(с профессиональным обучением)»

kovalenkocvn@mail.ru

Белокопытова Наталья Владимировна

заместитель директора по профессиональному обучению, МКОУ «Средняя общеобразовательная школа №9 города Аши Челябинской области

(с профессиональным обучением)» belkpytva@mail.ru

Луткова Алена Михайловна педагог-психолог, МКОУ «Средняя общеобразовательная школа №9 города Аши Челябинской области

(с профессиональным обучением)»

Alenikfedoseeva@ya.ru

Аннотация: В статье дано описание организационно-педагогических условий организации профессионального обучения старшеклассников в пределах освоения основной общеобразовательной программы среднего общего образования, основанном на опыте работы общеобразовательной организации. Актуальность заявленной темы отражает инновационную деятельность общеобразовательной организацией в условиях реализации основной образовательной программы среднего общего образования, интегрированной с основной программой профессионального обучения по профессии рабочего/ должности служащего. Цель настоящего исследования заключается в теоретическом обосновании и предоставлении опыта работы по реализации организационно-педагогических условий организации профессионального обучения старшеклассников на уровне среднего общего образования. В исследовании материалы отражают инновационную деятельность общеобразовательной организации в условиях реализации основной образовательной программы среднего общего образования, интегрированной с основной программой профессионального обучения по профессии рабочего/должности служащего. Использованы методы теоретического анализа, конкретизации, обобщения, синтез, дедукция, моделирование. Авторами описаны условия реализации основной образовательной программы среднего общего образования, интегрированной с основной программой профессионального обучения по профессии рабочего/должности служащего, которая позволит общеобразовательным организациям проектировать и реализовать основные образовательные программы с учетом региональной специфики и специфики общеобразовательной организации, особенностей контингента обучающихся в полном соответствии с федеральными государственными образовательными стандартами общего образования. В статье характеризуют описание организационно-педагогических условий организации профессионального обучения старшеклассников в пределах освоения основной общеобразовательной программы среднего общего образования, основанном на опыте работы общеобразовательной организации. Представленная модель региональной основной образовательной программы среднего общего образования раскрывает технологию проектирования в общеобразовательных организациях основных образовательных программ с учетом: а) особенно- 
educational organization (secondary school with vocational training). The work experience of the Moscow State Educational Institution «Secondary School No. 9 of Ashi (with professional training» is presented. In it, training is carried out only according to professional training programs for the professions of workers, positions of employees. In conclusion, the possibilities of applying the selected organizational and pedagogical conditions for the organization of educational practice in the design and implementation by educational institutions of secondary general education of the main professional educational programs for the training of workers / positions of employees in the development of educational and production programs are substantiated and presented.

Keywords: vocational training, vocational training, organizational and pedagogical conditions, individual educational trajectory. стей региона; б) содержания концепций модернизации предметных областей (информационные технологии, химия); в) специфики образовательной организации (средняя школа с профессиональным обучением). Представлен опыт работы МКОУ «СОШ № 9 г. Аши (с профессиональным обучением». В ней обучение осуществляется только по программам профессиональной подготовки по профессиям рабочих, должностям служащих. В заключении обоснованы и представлены возможности применения выделенных организационно-педагогических условий организации учебной практики при проектировании и реализации образовательными учреждениями среднего общего образования основных профессиональных образовательных программ подготовки рабочих/должностей служащих разработке программ учебных и производственных.

Ключевые слова: профессиональное обучение, профессиональная подготовка, организационно-педагогические условия, индивидуальная образовательная траектория.

\section{Введение}

A ктуальность проблемы и разработки в условиях модернизации системы отечественного образования в качестве одной из важнейших задач образовательного учреждения является организация оптимальных условий профессионального самоопределения личности, способной плодотворно жить в современном обществе и преобразовывать его, самостоятельно принимать верные, жизненно важные решения, позитивно самореализовываться в основных сферах жизнедеятельности, в том числе профессиональной.

Цель настоящего исследования заключается в теоретическом обосновании и предоставлении опыта работы по реализации организационно-педагогических условий организации профессионального обучения старшеклассников на уровне среднего общего образования.

\section{Особенности организационно-педагогических условий организашии профессионального обучения старшеклассников на уровне среднего обшего образования}

М.С. Пашоликов установил, что системообразующим фактором личностного самоопределения является «профессиональное самоопределение, понимаемое в педагогической науке как процесс формирования личностью своего отношения к профессионально-трудовой среде» (Е.А. Климов) [5]. Этот длительный процесс согласования внутриличностных и социально-профессиональных потребностей происходит на протяжении всего жизненного и профессионального пути.

Н. Стерхова и Н. Ипполитова [4] описывают понятие «условие» как:

1. обстоятельство, от которого что-нибудь зависит;
2. правила, установленные в какой-нибудь области жизни, деятельности;

3. обстановка, в которой что-нибудь происходит;

Эффективность профессионального самоопределения личности зависит от характера педагогического сопровождения данного процесса, управления данным процессом, то есть создания оптимальных условий для самостоятельного, осознанного выбора школьниками будущей профессиональной деятельности.

И.С. Арон склонен считать, что главный период выбора профессии приходится на старший школьный возраст. Для него характерны самоактуализация, принятие ответственных решений, определяющих всю дальнейшую жизнь человека. И это является важнейшим основанием взвешенного выбора учащимися качественного образования, соответствующего потребностям и способностям, траектории личностного развития, приоритетам в профессиональной сфере, ценностным ориентациям и индивидуально выраженным целям. Это связано с тем, что потребность в самоопределении является центральным моментом в социальной ситуации развития старшеклассников (Л.И. Божович, И.С. Кон, Е.А. Климов, Д.И. Фельдштейн, Д.Б. Эльконин и др.) [1].

Одной из ключевых идей профильного обучения является разработка индивидуальной образовательной траектории личности, поскольку она направлена на педагогическую поддержку индивидуальности школьника, развитие его интеллектуальной и эмоционально-волевой сфер, стимулирование творчества и духовности в условиях образовательной среды. В этом направлении активно работает МКОУ «СОШ № 9 г. Аши (с профессиональным обучением)».

Общеобразовательная организация с 2015 года яв- 
ляется региональной инновационной площадкой Челябинской области. За это время полностью реализованы два профориентационных проекта. Первый проект, «Подготовка кадров для региона», был связан с профессиональным обучением старшеклассников по профессиям, востребованным Ашинским районом. В результате работы над этим проектом в организации дополнительно разработаны программы профессионального обучения, которые реализуются для всех юношей города Аши и поселка Ук - «Токарь» и «Электромонтер по ремонту и обслуживанию электрооборудования» в тесном сотрудничестве с ПАО «Ашинский метзавод».

Далее, в 2017 году, школа снова становится площадкой РИП, победив в конкурсном отборе с программами, ориентированными на детей с ограниченными возможностями здоровья: «Овощевод с элементами цветоводства» и «Кроликовод».

Третий реализуемый проект называется «Профессия в школе». В результате работы над этим проектом организацией был разработан и уже реализуется учебный план среднего общего образования, интегрированный с программами профессионального бучения «Оператор ЭВиВМ» и «Лаборант химического анализа»

Цель проекта на текущем этапе его реализации заключается в создании организационно-педагогических условий образовательно-воспитательного пространства, построенного на интеграции общего образования и профессионального обучения, способного подготовить обучающегося к осознанному профессиональному выбору, повышающему уровень социальной адаптации и социальной мобильности.

Нормативная правовая база реализации основной образовательной программы среднего общего образования, интегрированной с основной образовательной программой профессионального обучения, сопровождается:

1. Федеральными и региональными документами, регламентирующими профессиональное обучение.

2. Локальными нормативными актами образовательной организации, регламентирующими образовательной процесс обучения старшеклассников с содержанием программ профподготовки.

Один из актуальных федеральных нормативных актов: Указ президента Российской федерации от 7 мая 2018 года №204 «О национальных целях и стратегических задачах развития Российской Федерации на период до 2024 года», в котором, среди прочих, прописаны следующие задачи:

- обновление содержания и совершенствование методов обучения предметной области «Технология»;
- формирование эффективной системы выявления, поддержки и развития способностей и талантов у детей и молодежи, основанной на принципах справедливости, всеобщности и направленной на самоопределение и профессиональную ориентацию всех обучающихся.

Нормативный акт «Комплекс мер по созданию условий для развития и самореализации учащихся в процессе воспитания и обучения на 2016-2020 годы» указывает, что развитие системы профессиональной ориентации и общественно-полезной деятельности учащихся должно строиться через совершенствование:

- нормативно-правовой

- организационно - управленческой

- научно-методической

- и кадровой составляющих

И задачами, поставленными данным «Комплексом мер» становятся:

- расширение форм профориентационной работы;

- предоставление учащимся возможности одновременно с получением среднего общего образования пройти профессиональную подготовку по выбранным ими профессиям.

Согласно Федеральному закону «Об образовании в Российской Федерации» от 29.12.2012 № 273-Ф3 [10], «образование подразделяется на общее, профессиональное, дополнительное образование и профессиональное обучение, обеспечивающие возможность реализации права на образование в течение всей жизни (непрерывное образование)» [10].

Согласно этому же закону, профессиональное обучение трактуется как «вид образования, который направлен на приобретение обучающимися знаний, умений, навыков и формирование компетенций, необходимых для выполнения определенных трудовых, служебных функций» (определенных видов трудовой, служебной деятельности, профессий).

Профессиональное обучение направлено на приобретение лицами различного возраста профессиональной компетенции, в том числе для работы с конкретным оборудованием, технологиями, аппаратно-программными и иными профессиональными средствами, получение указанными лицами квалификационных разрядов, классов, категорий по профессии рабочего или должности служащего без изменения уровня образования.

Профессиональное обучение по программам профессиональной подготовки в пределах освоения образовательной программы среднего общего образования, предоставляется бесплатно. 
В системе основных образовательных программ (согласно Федеральному закону «Об образовании в Российской Федерации» от 29.12.2012 №273-Ф3) [10] основные программы профессионального обучения подразделяются:

- программы профессиональной подготовки по профессиям рабочих, должностям служащих,

- программы переподготовки рабочих, служащих,

- программы повышения квалификации рабочих, служащих.

В МКОУ «СОШ № 9 г. Аши (с профессиональным обучением» обучение осуществляется только по программам профессиональной подготовки по профессиям рабочих, должностям служащих.

Программы профессионального обучения относятся к основным образовательным программам и могут реализовываться организацией, осуществляющей образовательную деятельность, как самостоятельно, так и посредством интеграции их в основную образовательную программу среднего общего образования. При этом могут использоваться различные образовательные технологии, в том числе дистанционные образовательные технологии, электронное обучение.

Профессиональное обучение может осуществляться лишь по тем профессиям рабочих и должностям служащих, которые указаны в приказе Минобрнауки России от 02.07.2013 №513 «Об утверждении Перечня профессий рабочих, должностей служащих, по которым осуществляется профессиональное обучение».

В Перечне профессий рабочих, сроки обучения по рабочим профессиям не регламентируются.

Согласно части 8 статьи 73 Федерального закона об образовании «продолжительность профессионального обучения определяется конкретной программой профессионального обучения, разрабатываемой и утверждаемой на основе установленных квалификационных требований (профессиональных стандартов) организацией, осуществляющей образовательную деятельность» [10].

Вместе с тем, при разработке образовательной программы профессионального обучения необходимо учитывать, что срок обучения зависит от времени, необходимого для приобретения знаний, навыков по определенной профессии и, кроме того, должен быть определен с учетом специфики профессии, необходимого уровня квалификации, сложности технологического процесса, мощности оборудования и иных особенностей, связанных с осваиваемой профессией. Существует нормативный акт, определяющий порядок реализации образовательных программ профессионального обучения. Это приказ Министерства просвещения Россий- ской Федерации от 26.08.2020 № 438 «Об утверждении Порядка организации и осуществления образовательной деятельности по основным программам профессионального обучения». Образовательные организации, осуществляющие образовательную деятельность по образовательным программам профессионального обучения, руководствуются в своей деятельности Федеральным законом и указанным приказом.

Согласно Порядка организации и осуществления образовательной деятельности по дополнительным профессиональным программам, образовательная деятельность обучающихся предусматривает следующие виды учебных занятий и учебных работ: лекции, практические и семинарские занятия, лабораторные работы, круглые столы, мастер-классы, деловые игры, тренинги, семинары по обмену опытом, выездные занятия, консультации, выполнение аттестационной, проектной работы и другие виды учебных занятий и учебных работ, определенные учебным планом.

Для всех видов аудиторных занятий академический час устанавливается продолжительностью 45 минут.

Согласно приказу Министерства образования и науки РФ от 17 мая 2012г. N 413 «Об утверждении федерального государственного образовательного стандарта среднего общего образования» - организация, осуществляющая образовательную деятельность: обеспечивает реализацию учебных планов одного или нескольких профилей обучения, а при наличии необходимых условий и профессионального обучения для выполнения определенного вида трудовой деятельности (профессии) в сфере технического и обслуживающего труда.

Необходимые организационно-педагогические условия:

1. Лицензия организации на право осуществления образовательной организацией профессионального обучения.

2. Внесение изменений в Устав образовательной организации.

3. Разработанные основные программы профессионального обучения (ОППО).

4. Разработанная основная общеобразовательная программа среднего общего образования (ООП СОО), интегрированная с ОППО.

5. Наличие в местности организаций и предприятий, где возможно прохождение производственной практики по выбранной профессии.

6. Утвержденный профстандарт выбранной профессии.

Все программы профессионального обучения разрабатываются на основе квалификационных требований (профессиональных стандартов). 
Следующее условие - наличие методического комплекса. Тут необходимо отметить, что литература должна быть не старше 5 лет, состоять в перечне допустимой учебной литературы по программам профессионального обучения. Если мы говорим о курсах, интегрированных в ООП СОО, то в данном случае литература должна состоять и в перечне допустимой учебной литературы для общеобразовательных организаций.

Одно из основополагающих условий реализации профессионального обучения в школе - наличие педагогических кадров со специальным образованием по реализуемой профессии и педагогическим образованием.

В связи с этим, за последние 3 года по направлению профессионального обучения было организовано прохождение курсов, необходимых для реализации всех программ (ОППО).

Наличие актуальной материально - технической базы к программам профессионального обучения, также является необходимым условием для реализации программ ОПППО.

Среди региональных актов, поддерживающих развитие профессионального обучения, можно назвать постановление правительства Челябинской области от 29 декабря 2017 года №756-П О государственной программе Челябинской области «Развитие профессионального образования в Челябинской области». Например, на такие подпрограммы государственной программы, как:

- «обеспечение доступности профессионального образования для инвалидов и лиц с ограниченными возможностями здоровья»;

- «поддержка фундаментальных научных исследований»;

- региональный проект «Молодые профессионалы» (повышение конкурентоспособности профессионального образования)», профессиональное обучение рассматривает как ориентир в своих целях и перспективах.

Частью 3 статьи 60 Федерального закона № 273-Ф3 установлено, что «лицам, прошедшим профессиональное обучение (даже внутри общеобразовательной программы) и успешно сдавшим квалификационный экзамен, выдается свидетельство о получении профессии (должности служащего), форма которого определяется самой организацией» [4].

Квалификационный экзамен включает в себя практическую квалификационную работу и проверку теоретических знаний в пределах квалификационных требо- ваний, указанных в квалификационных справочниках, и профессиональных стандартов по соответствующим профессиям рабочих, должностям служащих.

При освоении основной образовательной программы среднего общего образования, интегрированной с основной программой профессионального обучения, практическая квалификационная работа в нашей организации, согласно положению, засчитывается обучающемуся, прошедшему полное обучение, как индивидуальный итоговый проект обучающегося 11 класса и допускается к защите.

Лицам, успешно сдавшим квалификационный экзамен, выдается свидетельство о профессии рабочего, должности служащего.

Свидетельство о присвоении рабочей профессии соответствующего разряда выдается на основании приказа директора лично, прошедшему квалификационные испытания обучающемуся. Свидетельство регистрируется в книге регистрации выдачи квалификационных документов с присвоением каждому уникального номера.

Одним из важнейших условий реализации программы, содержащей профессиональное обучение, является организация и проведение производственной практики обучающихся. Производственная практика включает в себя обучение в условиях производства, где ребята отрабатывают умения и навыки выполнения трудовых операций и трудовых процессов, которые невозможно или нецелесообразно осваивать в учебных мастерских.

Производственная практика, организованная для обучающихся, формирует целостное представление ребят о профессии, технике, устройствах конструкций. Обучающиеся по программе, прошли все процедуры трудоустройства на предприятии: получили медицинский допуск, познакомились с наставниками, назначенными приказом предприятия для ведения практики, завели производственные дневники и получили свои заслуженные отзывы и отметки. Практические задания позволили освоить специфику профессии, увидеть её значимость на реальном большом производстве!

Новые программы и появление нового оборудования для обучающихся, значительно повлияло на возросший интерес к обучению в области информационных технологий и химии.

Для ребят, обучающихся на «Оператора ЭВиВМ» с умением программирования станков с ЧПУ оказалось полезным и увлекательным разработка программ изготовления реальных предметов: шахматных фигур, предметов быта, поделок на различные конкурсы. Под руководством учителя старшеклассники с удовольствием 
разрабатывают программы и участвуют от своего профиля в муниципальных конкурсах.

Появились результаты, связанные с освоением ребятами программы элективного курса. Например, команда МKOУ «СОШ № 9 г. Аши (с профессиональным обучением)», стала победителем в заочном этапе Межрегионального химического турнира ЧелГу. В сентябре этого года ребята не однократно выходили на улицы города с акцией «Мониторинг окружающей среды». Ребята проверяли почву и воду из реки на содержание хлоридов, тяжелых металлов, железа. Определяли цветность и жесткость воды, составили аналитические отчеты.

Команды школы ежегодно участвуют и в открытом региональном этапе конкурса WorldSkils в номинациях «Лаборант химического анализа», «Инженерный дизайн CAD». Эти возможности также открывает наличие нового оборудования, позволяющего готовить ребят к таким конкурсам. Команда юных химиков вышла в очный этап Турнира отличников наук «НьЮТОН». Таким образом, промежуточные результаты реализации проекта обеспечивают формирование, совершенствование, развитие личностных, предметных и метапредметных результатов обучающихся.

Модель интеграции образовательной и профессиональной программ осуществляется не только на занятиях элективных курсов, но и проявляется в различных формах работы, реализуемых на уроках через межпредметные и междисциплинарные связи, в рамках внеурочной деятельности - демонстрируя единство теоретических и практических знаний.

Итоговой формой аттестации по профессиональному обучению является квалификационный экзамен, который проверяет готовность обучающегося к выполнению соответствующей профессиональной деятельности и сформированности у него компетенций. На квалификационный экзамен ребята вышли с защитой итогового проекта по освоенному курсу, который пишется ребятами по результатам освоения програм- мы и отработки навыков, проведения исследований, опытнической работы на учебной и производственной практике. Для проведения квалификационного экзамена была создана квалификационная комиссия. Такая комиссия создается приказом директора. Согласно Положению о квалификационном экзамене, созданная комиссия должна состоять из сотрудников организации. Комиссию квалификационного экзамена с присвоением квалификации возглавляет директор школы, являющийся председателем комиссии, и в обязательном порядке приглашается представитель организации - работодателя, который контролирует соответствие полученных обучающимся знаний профстандарту выбранной профессии.

\section{ЗакАючение}

Опыт работы школы № 9 города Аши по интеграции программ среднего общего образования и профессионального обучения интересен и востребован многими муниципалитетами Челябинской области.

Опираясь на существующие в современной педагогической литературе подходы (В.А. Беликов, Н.В. Ипполитова, С.Н. Павлова, А.В. Сверчков, Е.И. Козырева, Н.С. Стерхова, М.И. Шалин и др. [5],[6]) в контексте работы по проекту «организационно-педагогические условия» понимаются как меры, обеспечивающие создание профессионально-образовательной среды, реализация которых способствует повышению результативности организации учебной практики.

Содержание организационно-педагогических условий: создание актуальной нормативной базы, организации учебной практики в школьных мастерских, производственной практики, построение системы социального партнёрства между общеобразовательной организацией и организациями города, помогает достичь важной цели: обеспечить обучающимся опыт конструирования профессионального выбора и прогнозирования личного успеха в интересующей сфере профессиональной деятельности.

\section{ЛИТЕРАТУРА}

1. Арон И.С. Профессиональное самоопределение старшеклассников в контекстесоциальной ситуации развития [Электронный ресурс] / И.С. Арон.- Национальный психологический журнал №3 (11).-2013, c.20-27/ URL: http:// https://cyberleninka.ru/article/n/professionalnoe-samoopredelenie-starsheklassnikovv-kontekstesotsialnoy-situatsii-razvitiya/(дата обращения: 22.05.21)

2. Единый квалификационный справочник должностей руководителей, специалистов и служащих. [Электронный pecypc]. URL: http://www.consultant.ru/ document/cons_doc_LAW_97378/(дата обращения: 22.05.21)

3. Государственная программа Российской Федерации «Развитие образования на 2013-2020 годы» (Распоряжение Правительства Российской Федерации от 15.05.2013 г. № 792) [Электронный источник] / http://base.garant.ru/70643472/ (дата обращения 21.05.2021

4. Ипполитова Н.В., Стерхова Н.С. Анализ понятия «педагогические условия»: сущность, классификация /Н.В. Ипполитова, Н.С. Стерхова // General and Professional Education. - 2012. - №1. - c. 8-14. 
5. Пашоликов М.С. Управление событиями. Стратегия. Тактика. Практика. Руководство по организации молодежных событий / Российский государственный педагогический университет им. А.И. Герцена, институт экономики и управления. Санкт-Петербург, 2019. - 51 с.

6. Иванова Е.М. Субъектно-деятельностная концепция профессионального труда Е.А. Климова и её научно-практическая ценность/Климова Е.М.//Вестник Московского университета.-№2.[Электронный источник] / https://cyberleninka.ru/article/n/subektno-deyatelnostnaya-kontseptsiya-professionalnogo-trudae-a-klimova-i-ee-nauchno-prakticheskaya-tsennost (дата обращения 21.05.2021

7. Сверчков А.В. Организационно-педагогические условия формирования профессионально-педагогической культуры будущих спортивных педагогов / Сверчков А.В. // Молодой ученый. — 2009. — № 4. — С. 279-282.

8. Указ Президента РФ от 07.05.2012 N 599 «0 мерах по реализации государственной политики в области образования и науки» [Электронный источник] / http://www.consultant.ru/document/cons_doc_LAW_129346/ (дата обращения 21.05.2021)

9. Федеральный закон от 06.10.2003 N 131-Ф3 (ред. от 29.12.2017) «06 общих принципах организации местного самоуправления в Российской Федерации» [Электронный источник] / http://www.consultant.ru/document/cons_doc_LAW_44571/ (дата обращения 21.05.2021)

10. Федеральный закон от 29.12.2012 N 273-Ф3 (ред. от 07.03.2018) «06 образовании в Российской Федерации» [Электронный источник] / http://www. consultant.ru/document/cons_doc_LAW_140174/ (дата 0бращения 21.05.2021)

(c) Коваленко Светлана Николаевна (kovalenkocvn@mail.ru), Белокопытова Наталья Владимировна (belkpytva@mail.ru), Луткова Алена Михайловна (Alenikfedoseeva@ya.ru).

Журнал «Современная наука: актуальные проблемы теории и практики» 